Article

\title{
A Common Variant of PROK1 (V67I) Acts as a Genetic Modifier in Early Human Pregnancy through Down-Regulation of Gene Expression
}

\author{
Mei-Tsz Su ${ }^{1}$, Jyun-Yuan Huang ${ }^{1}$, Hui-Ling Tsai ${ }^{1}$, Yi-Chi Chen ${ }^{2}$ and Pao-Lin Kuo ${ }^{1, *}$ \\ 1 Department of Obstetrics and Gynecology, National Cheng Kung University Hospital, College of Medicine, \\ National Cheng Kung University, Tainan 704, Taiwan; sumeitsz@mail.ncku.edu.tw (M.-T.S.); \\ yyuangtw@mail.ncku.edu.tw (J.-Y.H.); cuteyling@gmail.com (H.-L.T.) \\ 2 Department of Economics, National Cheng Kung University, Tainan 704, Taiwan; yichi@mail.ncku.edu.tw \\ * Correspondence: paolink@mail.ncku.edu.tw; Tel.:+886-6-235-3535 (ext. 5222); Fax: +886-6-276-6185
}

Academic Editor: Constantinos Stathopoulos

Received: 7 December 2015; Accepted: 16 January 2016; Published: 27 January 2016

\begin{abstract}
PROK1-V67I has been shown to play a role as a modifier gene in the PROK1-PROKR system of human early pregnancy. To explore the related modifier mechanism of PROK1-V67I, we carried out a comparison study at the gene expression level and the cell function alternation of V67I, and its wild-type (WT), in transiently-transfected cells. We, respectively, performed quantitative RT-PCR and ELISA assays to evaluate the protein and/or transcript level of V67I and WT in HTR-8/SV neo, JAR, Ishikawa, and HEK293 cells. Transiently V67I- or WT-transfected HTR-8/SV neo and HEK293 cells were used to investigate cell function alternations. The transcript and protein expressions were down-regulated in all cell lines, ranging from $20 \%$ to $70 \%$, compared with WT. There were no significant differences in the ligand activities of V67I and WT with regard to cell proliferation, cell invasion, calcium influx, and tubal formation. Both PROK1 alleles promoted cell invasion and intracellular calcium mobilization, whereas they had no significant effects on cell proliferation and tubal formation. In conclusion, the biological effects of PROK1-V67I on cell functions are similar to those of WT, and the common variant of V67I may act as a modifier in the PROK1-PROKR system through down-regulation of PROK1 expression. This study may provide a general mechanism that the common variant of V67I, modifying the disease severity of PROK1-related pathophysiologies.
\end{abstract}

Keywords: modifier gene; Prokineticin 1 (PROK1; EG-VEGF); recurrent miscarriage; calcium influx; cell invasion

\section{Introduction}

Prokineticin 1 (PROK1), also known as endocrine gland-derived vascular endothelial growth factor (EG-VEGF), is a small, secreted peptide that belongs to the prokineticin family [1]. PROK1 is a tissue-specific proangiogenetic mitogen and chemotactic factor, and it acts through activation of two cognate G-protein-coupled receptors (GPCRs), prokineticin receptor 1 (PROKR1) and prokineticin receptor 2 (PROKR2). The expression of PROK1 is predominantly in the steroidogenic glands, such as ovary, testis, adrenal cortex, and placenta [2-4], and has been shown to have a wide range of functions including angiogenesis, modulation of inflammatory responses, and regulation of hematopoiesis) $[5,6]$.

In recent years, PROK1 has been shown to play a role in female reproduction and human pregnancy. The temporal and spatial expression of PROK1, and its receptors in ovary and early gestational tissue, highlights their functions in follicular maturation, luteal angiogensis, embryo implantation, and uterine receptivity $[1,7,8]$. The dynamic expression and regulation profile of the PROK1-PROKR system through human pregnancy also suggests its regulatory role in the process of 
placental development and initiation of parturition [9-11]. Previous publication had shown that PROK1 inhibits and controls trophoblast invasion in human pregnancy [12], whereas a recent prospective study suggested PROK1 may facilitate an embryo endowing with adequate implantation potential [13]. Moreover, aberrant expression or activity of PROK1 and its receptors are also reported to be associated with several gestational complication, and most were related to inadequate or inappropriate trophoblast invasion, such as gestational trophoblastic diseases, recurrent pregnancy losses, preeclampsia, and intrauterine fetal growth restriction [11,14-16].

A common polymorphism of PROK1, V67I (c.199 G>A, rs7514102), located in the first nucleotide of exon 3 , is a non-synonymous substitution resulting in amino acid change from valine (V) to isoleucine (I). The frequency of $\mathrm{G}$ to A transition varies among different ethnicities, and ranges from $43 \%$ to $64 \%$ in the general population ( $43 \%$ in Caucasians, $54 \%$ in Han Chinese, $64 \%$ in Japanese, and $46 \%$ in Nigerians, with this data taken from http://www.ncbi.nlm.nih.gov/pubmed/). The evolution of V67I is highly conserved, and the change of amino acid from $V$ to I seems neutral. However, the impact of this genetic variant in the PROK1 system and its clinical relevance have not yet been explored.

We recently reported the PROK1 variant (V67I) act as a genetic modifier in human early pregnancy [17]. Previous studies of recurrent pregnancy loss (RPL) showed that women carrying PROKR1 and PROKR2 variants (I379V and V331M) have less susceptibilities for RPL risk, and that trophoblastic cell function alternation by enhancing cell invasiveness may provide the protection from recurrent abortion $[17,18]$. In contrast, the protection effect of the PROKR1/2 variant may be attenuated if the woman also carries PROK1-V67I [17]. Although genetic association research showed evidence of these effects, the underlying mechanism of the common variant of PROK1 (V67I) with regard to modifying RPL risk remains unclear. In order to better understand the critical role of PROK1 in physiological and pathological pregnancy, this study aimed to explore the modification role of PROK1-V67I and compare various cell functions to those of its wild-type (WT) in several associated cell lines. The results of this study may provide a general mechanism of a common variant's effect on PROK1-related disorders.

\section{Results}

\subsection{V67I Is a Common PROK1 Variant in the General Population}

We analyzed the coding regions of PROK1 using the Sanger sequence in 142 RPL women and 149 normal controls in a previous report [17]. The allele and genotype frequencies of PROK1-V67I variant (c.199 G>A, rs7514102) and wild-type (WT) showed no significant differences between RPL and control groups, and the pooled data are $51 \%, 21 \%$ and $28 \%$ for GG, GA, and AA genotypes. The highly-conserved V67I variant of PROK1 is located in the first nucleotide of exon 3, and the G to A transition changes the amino acid from Valine (V) to Isoleucine (I) (Figure 1). We further compared the population diversity of V67I using HapMap data from NCBI (http://www.ncbi.nlm.nih.gov/pubmed/). In general, the frequency of the G to A transition is around $50 \%$, ranging from $39 \%$ to $64 \%$, and varies among different populations (Table 1 ).

Table 1. Population diversity of PROK1 wild-type and V67I (c.199 G>A, rs7514102) variant.

\begin{tabular}{lcccccc}
\hline \multirow{2}{*}{ Population } & \multirow{2}{*}{ Group/Sample Count } & \multicolumn{3}{c}{ Genotype Frequency } & \multicolumn{2}{c}{ Allele Frequency } \\
\cline { 3 - 7 } & & GG & GA & AA & G & A \\
\hline HapMap-CEU & European/118 & 0.339 & 0.458 & 0.203 & 0.568 & 0.432 \\
HapMap-HCB & Asian/90 & 0.200 & 0.511 & 0.289 & 0.456 & 0.544 \\
HapMap-JPT & Asian/90 & 0.089 & 0.533 & 0.378 & 0.356 & 0.644 \\
HapMap-YRISub-Saharan African/120 & 0.319 & 0.450 & 0.233 & 0.542 & 0.458 \\
\hline
\end{tabular}

Reference data of HapMap population diversity was derived from NCBI (updated 2015.6.24); GTC: Valine (V); ATC: Isoleucine (I); CEU: Utah Residents with Northern and Western European Ancestry; HCB: Han Chinese in Beijing, China; JPT: Japanese in Tokyo, Japan; YRI: Yoruba in Ibadan, Nigeria. 
A

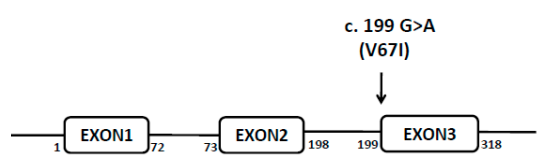

B
C
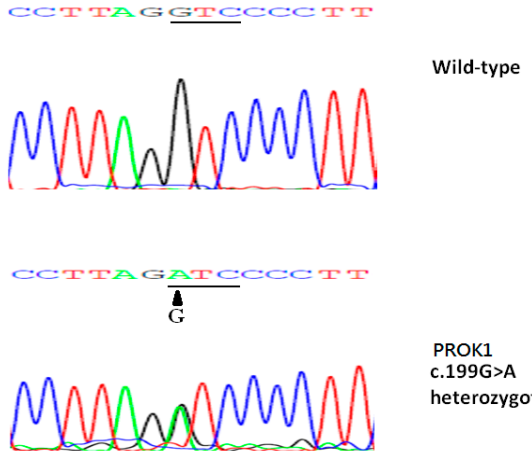

PROK1

c.199G $>\mathrm{A}$

heterozygote

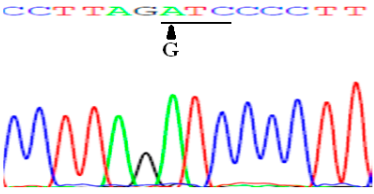

PROK1

homozygote

Figure 1. (A) Schematic of PROK1 variant (c.199G>A; p.Val67Ile); (B) PROK1 variant (V67I) is conserved in mammals; (C) Representative chromatographs showing the heterozygous and homozygous c.199G $>A$, p.Val67Ile variants and wild-type (WT) sequences.

\subsection{Down-Regulated Gene Expression of V67I in the Transcript and Protein Levels Compared with Wild-Type}

In order to evaluate gene expressions of PROK1-V67I and -WT, we compared different cells transfected with V67I or WT plasmids in the transcript and protein levels using qRT-PCR and ELISA assays, respectively. The transcript expression of V67I compared with WT was 50.5\% in HEK-293 and $64 \%$ in HTR-8/SV neo cells (Figure 2A, $p<0.001$ ). When comparing the protein levels in the cell lysate and supernatant of the culture medium, the protein expression of V67I was also down-regulated in the HEK293 (42.5\%-47.5\%), and HTR-8/SV neo (60\%-71\%) cells and showed similar results to those found for the transcript expression (Figure 2B). We further investigated the protein expression of V67I in JAR and Ishikawa cells to evaluate cell specificity, and detected lower expressions of V67I in both the cell lysate and supernatant of the culture medium in the JAR $(19.6 \%-22.2 \%)$ and Ishikawa $(30.1 \%-36.9 \%)$ cells (Figure $2 \mathrm{~B}, p<0.001)$. The basal protein concentration in non-transfected cells (Mock) were between 11 and $28 \mathrm{pg} / \mathrm{mL}$ in each cell line (HEK293 cells: $10.84 \pm 0.85 \mathrm{pg} / \mathrm{mL}$; HTR-8/SV neo cells: $27.93 \pm 0.94 \mathrm{pg} / \mathrm{mL}$; JAR cells: $13.77 \pm 0.88 \mathrm{pg} / \mathrm{mL}$; Ishikawa cells: $15 \pm 0.38 \mathrm{pg} / \mathrm{mL}$ ).

A

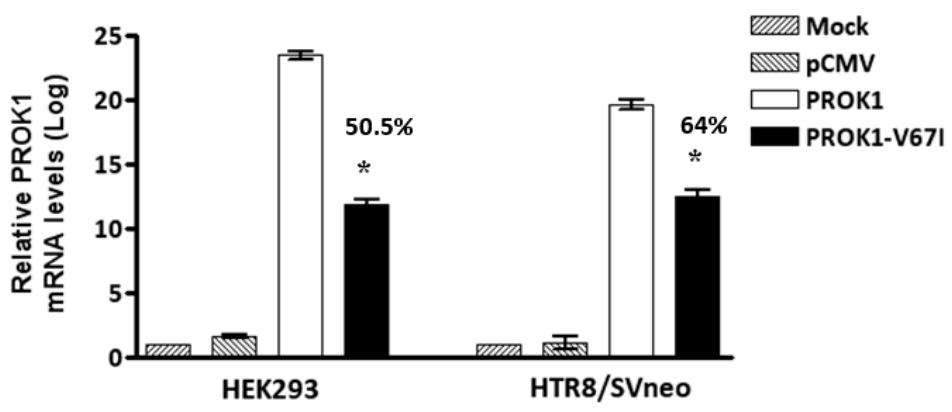

Figure 2. Cont. 


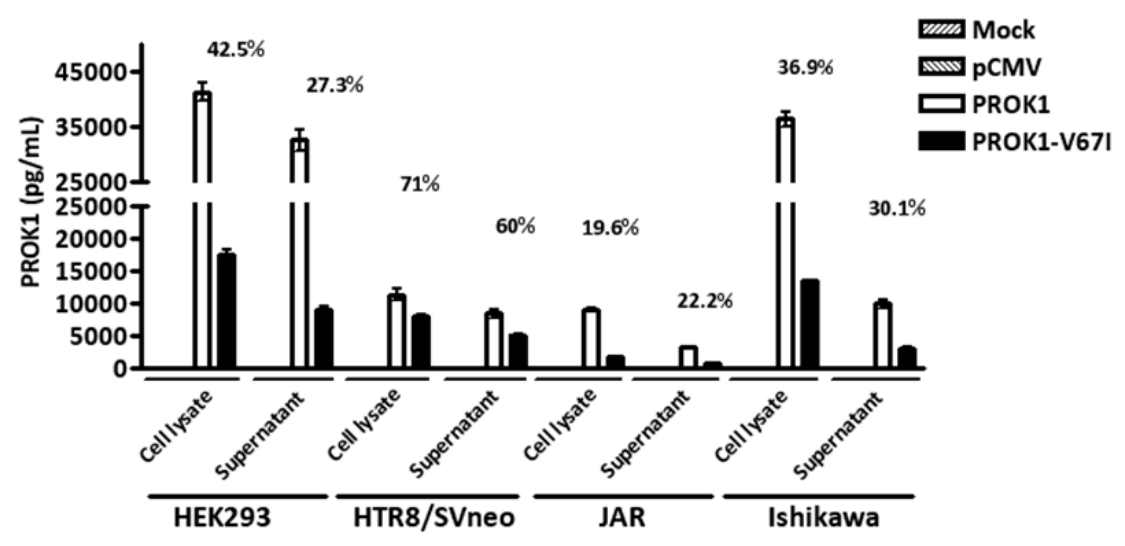

Figure 2. Decreased gene expression of PROK1 variant (V67I) compared with wild-type (WT) in different cell lines. Cells were transiently transfected with either WT or variant PROK1 construct for $48 \mathrm{~h}$. (A) Quantitative RT-PCR analysis showed decreased transcript level of V67I compared with WT in cell lines (HEK293 cells: 50.5\%; HTR-8/SV neo cells: 64\%); (B) ELISA analysis showed consistently decreased protein concentrations in the cell lysate and supernatant of the culture medium among different cell lines (HEK293 cells: 42.5\%-47.5\%; HTR-8/SV neo cells: 60\%-71\%; JAR cells: 19.6\%-22.2\%; and Ishikawa cells: $30.1 \%-36.9 \%$ ). The comparison of V67I and WT is shown in percentages. Data are presented as means \pm SEM. ${ }^{*} p<0.001$ compared with the corresponding control (WT). Mock: cells without transfecting any vectors; pCMV: cells with transfecting empty control vectors.

\subsection{PROK1 Wild-Type and Variant (V67I) Have No Significantly Different Effects on Cell Proliferation and Tubal formation}

Cell proliferation and angiogenesis are critical in the stages of implantation, embryogenesis, and placentation. We examined if PROK1 and its V67I variant altered the abilities of cell proliferation and tube organization, following their individual ectopic expression in cells. When comparing an empty control vector, variant, and wild-type PROK1, the cell numbers of transfected HEK293 and HTR-8/SV neo cells were not significantly different after 1 to 4 days of cell culture, based on the results of a cell viability assay (Figure 3A). To evaluate the angiogenic ability of PROK1 WT and its variant (V67I), we measured capillary tube formation of PROK1- or V67I-transfected cells by calculating branching length between two nodes at different time intervals (4-6 h). After $4 \mathrm{~h}$ incubation on the Matrigel, HEK-293 and HTR-8/SV neo cells rapidly reorganized and subsequently formed tube-like structures on Matrigel. Average tubal length was measured in each group, and there was no stimulatory effect on tube formation in PROK1- and V67I-transfected HEK-293 and HTR-8/SV neo cells compared with those of the empty control vector group (Figure 3B). In addition, both PROK1 and V67I groups behaved similarly, without any effects on tube formation in HEK 293 or HTR-8/SV neo cells. The results, thus, showed that PROK1 and V67I did not have any effects on cell proliferation and tubal organization in either cell line. 
A
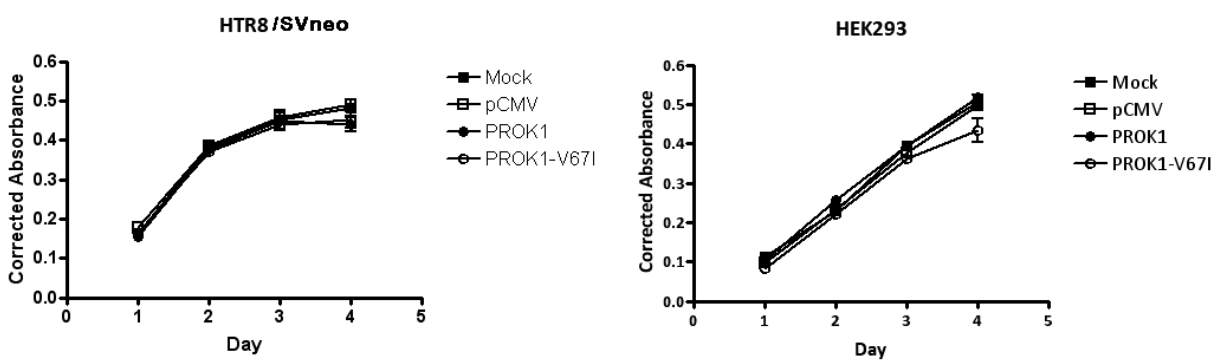

B
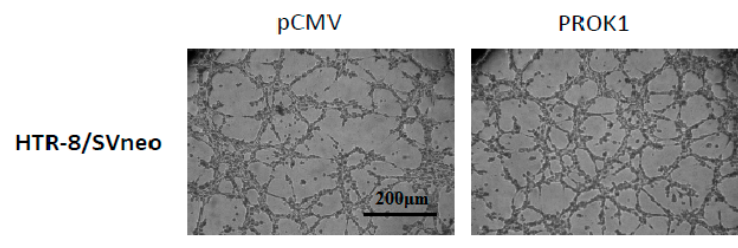

PROK1-V67I

HEK293
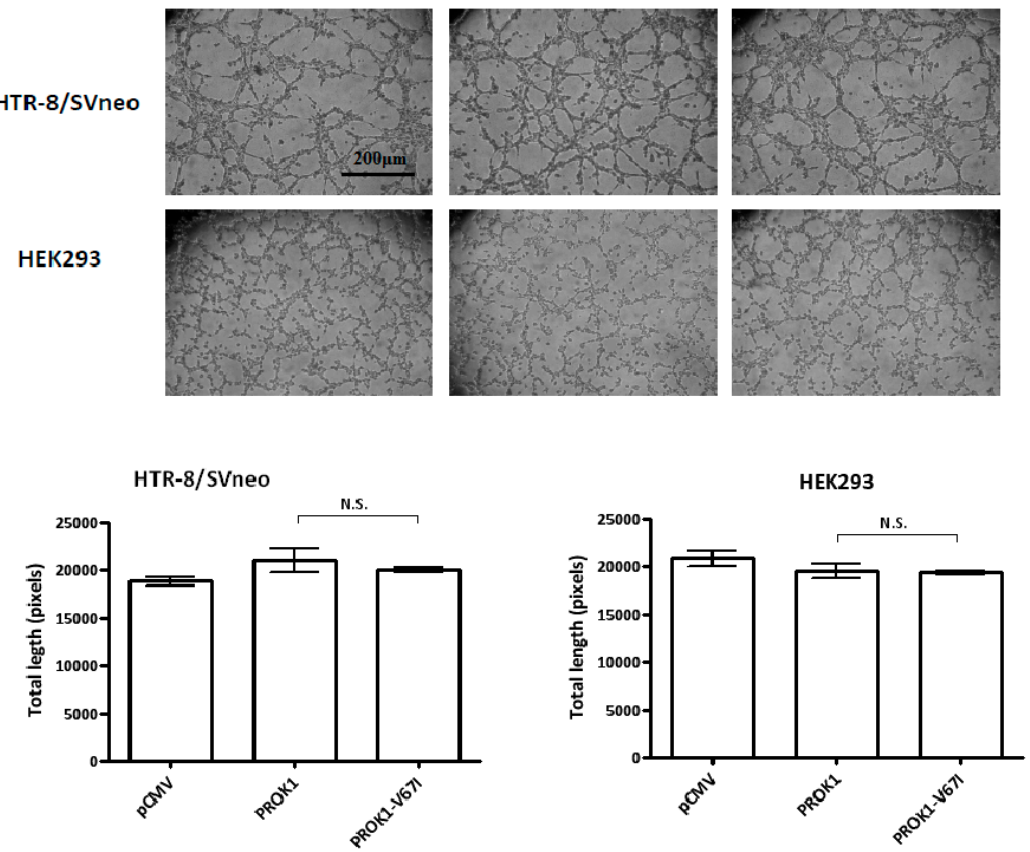

Figure 3. PROK1-V67I and WT did not alter cell proliferation and tubal formation. HEK 293 and HTR-8/SV neo cells were transiently transfected with control vector, WT, or variant PROK1 construct. (A) Cell numbers in proliferation of HEK293 and HTR-8/SV neo cells were measured, and no significant differences were detected between each group; (B) Photographs and quantification of tube formation in each group of HTR-8/SV neo and HEK293 cells, and no significant difference (N.S.) was detected.

\subsection{Both PROK1 Wild-Type and Its Variant (V67I) Increase Cell Invasion and Activate Intracellular Ca Influx in a Dose-Dependent Manner}

In the stages of embryo implantation and further placentation, it is critical that appropriate and adequate trophoblast cell invasion is achieved. We performed cell invasion assay in a trans-well system, and found that PROK1- and V67I-expressing HEK293 and HTR-8/SV neo cells had enhanced abilities of cell invasion (Figure $4 \mathrm{~A}, p<0.001$ ), but there was no difference in this enhancement between the PROK1 and V67I variant groups. We further evaluated the cell invasion ability in the prokineticin receptor 1 (PROKR1)- or prokineticin receptor 2 (PROKR2)-transfected cells, and both cell invasion abilities increased in a dose-dependent manner after treating with concentrated PROK1 and V67I $(0,1.0$, 2.5, and $5.0 \mathrm{nM}$ ) from conditioned medium (Figure 4A, lower panel). In addition, PROKR2-transfected cells had a significantly enhanced cell invasiveness compared with PROKR1-transfected cells at 0, 1.0, and $2.5 \mathrm{nM}$ of PROK1 or V67I treatment, but did not show significance at $5.0 \mathrm{nM}$ (Figure 4A, lower panel). 


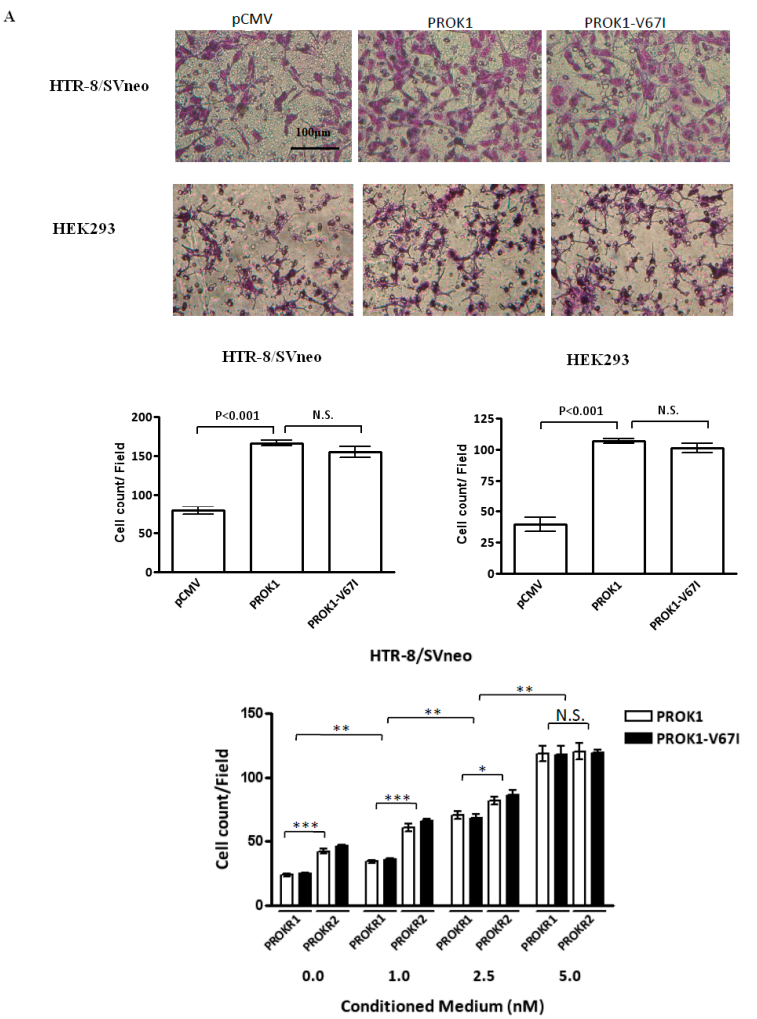

B

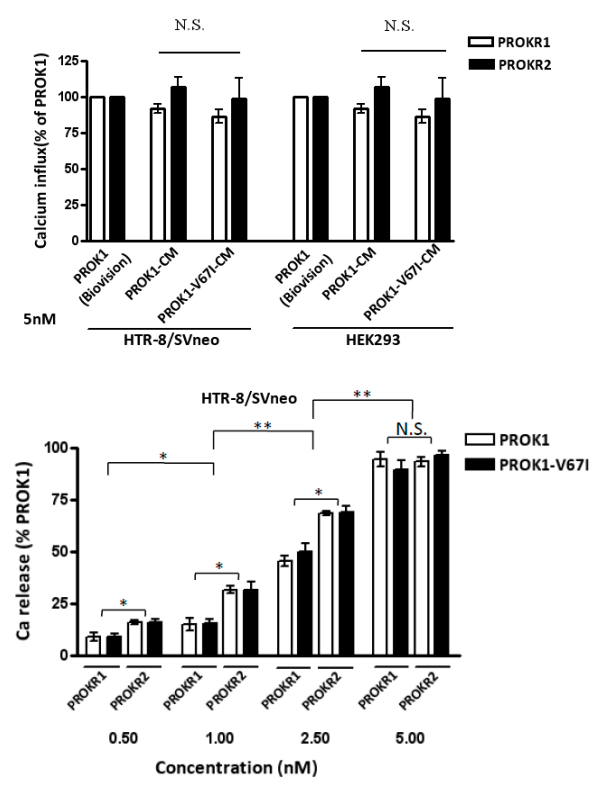

Figure 4. PROK1-V67I and -WT (A) enhanced cell invasion ability and (B) altered intracellular calcium influx in a dose-dependent manner. PROKR2-transfected cells had increased abilities of inducing calcium release and cell invasiveness compared with PROKR1-transfected cells. HEK 293 and HTR-8/SV neo cells were transiently transfected with control vector, WT or variant PROK1 construct. Photographs and quantification of invaded cells stained with Giemsa's azur eosin methylene blue solution are shown in the upper and middle panels in A. HEK293 and HTR-8/SV neo cells were transiently transfected with either PROKR1 or PROKR2 plasmid and treated with various concentrations of PROK1 WT or V67I condition medium (0, 1.0, 2.5, $5.0 \mathrm{nM})$. Invaded cells (A, lower panel) and intracellular cell influx alternation (B, upper and lower panels) were measured. ${ }^{*} p<0.05$; ${ }^{* *} p<0.01 ;{ }^{* *} p<0.001$ compared between PROKR1- and PROKR2-transfected cells, and groups of different concentration. PROK1 recombinant protein (Biovision, Milpitas, CA, USA) was used as a standard control to validate protein function of PROK1 (WT) and PROK1-V67I in condition medium (CM). N.S.: no significant difference. 
Calcium signaling is a critical function index that is used to evaluate $G$ protein-coupled receptors (GPCRs) and their ligand activities. We evaluated PROK1-induced intracellular calcium mobilization by using a fluorescence-based assay in the prokineticin receptor 1 (PROKR1)- or prokineticin receptor 2 (PROKR2)-overexpressed cells. In this assay, HEK293 and HTR-8/SV neo cells were initially transfected with PKOKR1 or PROKR2 plasmid to enhance the amplitude of calcium signaling before investigation. The intracellular calcium influx was stimulated, but no significant differences were seen in the PROKR1- or PROKR2-transfected cells after treating with $5 \mathrm{nM}$ PROK1 or V67I from conditioned medium (Figure 4B, upper panel). Although the induced calcium influx showed a dose-dependent response after treating with PROK1 or V67I conditioned medium $(0.5,1.0,2.5,5.0 \mathrm{nM})$, there was no difference in the stimulation effect between PROK1 and V67I (Figure 4B, lower panel). By comparing PROKR1- and PROKR2-transfected cells on calcium signaling, PROKR2-transfected cells had a stronger signaling under concentration $0.5,1.0$, and $2.5 \mathrm{nM}$ of PROK1 or V67I treatment, but did not show significance at $5.0 \mathrm{nM}$ (Figure 4B, upper and lower panel).

\section{Discussion}

In a previous genetic association study of recurrent pregnancy loss (RPL), a PROK1 variant (V67I) was shown to be a genetic modifier gene in early human pregnancy [17]. We evaluated the functional effect of this common variant and compared it to PROK1-WT in order to investigate the possible mechanism of genetic modification in this study. We demonstrated that the conserved non-synonymous variant of PROK1 (V67I) has similar cell functions with regard to enhancing trophoblast cell invasion and stimulating intracellular calcium signaling compared with its wild-type. However, the gene expression of V67I is down-regulated in both transcript and protein levels across all associated cell lineages.

The biological interaction of PROK1 and PROKR1/2 is a ligand-receptor relationship. The impact of an amino acid change in PROK1 on the protein activity and the binding affinity between its receptors remain unclear, and no PROK1 variants have been reported before. We identified PROK1-V67I to be the only non-synonymous variant in the coding regions of PROK1 using Sanger sequence in 291 subjects (142 RPL patients and 149 normal controls) [17]. The non-synonymous variant of PROK1-V67I is so common that it is possessed by nearly $50 \%$ of the general population, appears to have no visible effect on the fitness of individuals and is, therefore, usually considered as a neutral variant. However, several studies have demonstrated that a common non-synonymous variant may have an association with or functional significance for the pathophysiology of a disease [19-21]. From an evolutionary perspective, the common non-synonymous variants usually have modest structural effects, and some of them are simply functionally neutral, while others are deleterious [22]. Moreover, some variant sites that are predicted to be deleterious might have advantages under unique conditions of developmental or environmental changes [22]. During the early stages of placental development, the coordination of cell proliferation, differentiation, and invasion of trophoblasts is subtle and fine-tuned in the feto-maternal interface. The lower protein production of V67I seems to have a negative effect on the function of PROK1, which implies less cell invasion ability and attenuated downstream calcium signaling. However, whether the down-regulated PROK1 expression is beneficial or deleterious is an issue that requires more research.

The PROK1 level during pregnancy is dynamic, both in placental tissue and serum collected from pregnant women. Placental PROK1 expression gradually rises after embryo implantation and peaks at 8-11 weeks of gestation, subsequently decreasing until the end of the first trimester, and then this level is maintained throughout the remaining gestation $[4,7,23]$. Plasma PROK1 concentration also gradually increases during the first trimester $(\sim 200 \mathrm{pg} / \mathrm{mL})$, and then decreased to $\sim 70-80 \mathrm{pg} / \mathrm{mL}$ in the second and third trimesters [23]. Adequate trophoblast invasion and proper placental development ensures the embryo or fetus has sufficient nutrient and oxygen, and PROK1 is regarded as playing a critical role in regulating trophoblast invasion and placental development $[13,23]$. Excessive trophoblast invasion could result in placenta accreta and invasive moles, whereas poor trophoblast invasion of 
maternal vessels could contribute to preeclampsia and intrauterine fetal growth restriction $[10,13,23,24]$. As a result, the differential down-regulated PROK1 expression of V67I in different cell lineages presented in this study could be an underlying cause for a pathological condition, or a normal regulatory mechanism of the PROK1 system in human pregnancy. We, therefore, speculated that women carrying different PROK1 genotypes may have varied susceptibility to different pregnancy complications. Moreover, PROK1 was shown to be up-regulated in several types of cancers, such as colorectal cancer, pancreatic cancer, prostate cancer, and ovarian cancer [25-30], and was regarded as a poor prognostic marker and survival factor. These PROK1-related malignancies were closely associated with advanced clinical stage, histological grade, and distant metastasis, which may probably through regulating peritumoral angiogenesis or/and strengthened cancer cell invasiveness [25-30]. The PROK1-overexpressing cells in the present study could be a mimicking condition of malignancy, and the increased cell invasion ability suggested the potential role of PROK1 in cancer biology. Nevertheless, more studies are required to elucidate the role of PROK1 WT and V67I in both human pregnancy and cancers, and the complex interaction between PROK1 and its receptors in various pathophysiologies of human clinical situations.

Disease severity could be influenced by different genetic backgrounds, and genetic modifiers are known to alter the outcomes in various human diseases or animal models of disease, such as muscular dystrophy (MD), epidermolysis bullosa (EB), and some motor neuron diseases [31-35]. Since genetic modifiers act in a non-Mendelian manner to alter the phenotype in question, the comparatively small effect of V67I in the general population is highly consistent with its role as a modifier in early human pregnancy. From our previous data, PROKR1 and PROKR2 variants (I379V and V331M) may protect women from RPL through enhanced trophoblast invasiveness, thus facilitating embryo implantation [18]. In women carrying wild-types of PROKR1 and PROKR2, the genotypes of PROK1 WT or V67I do not have significant effects on RPL risk. In contrast, women carrying V67I will lose the protective effect with regard to RPL risk if they also carry PROKR1 or PROKR2 variants, indicating that PROK1-V67I modifies RPL risk in specific populations [17]. This could be explained by the results of the cell functional assays carried out in the present study. These showed that the effects of V67I on cell function are not different from those of its wild-type, although its gene expression efficiency is only $20 \%-70 \%$ that of the latter (depending on cell types). The ability of trophoblast invasion is promoted by PROK1 and V67I, and both facilitate invasiveness in a dose-response manner. Therefore, PROK1-V67I may reduce PROKRs' protective effect of promoting cell invasiveness by decreasing PROK1 protein production.

\section{Experimental Section}

\subsection{Subjects}

The present study was approved by the Institutional Review Board of National Cheng Kung University Hospital (\#HR-96-39) (Tainan, Taiwan), and informed consents were obtained from all patients and controls. The clinical and molecular details of the RPL subjects examined in the current work were reported in a previous study $[17,18]$. In this study we compared the V67I allele and genotype frequencies of our population, Han Chinese individuals in Taiwan, with those of other HapMap Populations (Table 1).

\subsection{Cell Cultures and Treatments}

The human HTR-8/SVneo trophoblast cell line was a gift from Dr. Charles Graham (Queen's University, Kingston, ON, Canada). HTR-8/SVneo cells were grown in RPMI 1640 medium (Invitrogen, Grand Island, NY, USA) supplemented with 10\% fetal bovine serum (FBS) and $100 \mathrm{IU} / \mathrm{mL}$ penicillin-streptomycin. The human embryonic kidney cell line (HEK293) were grown in Dulbecco Modified Eagle's Medium (DMEM) (Invitrogen) supplemented with 10\% FBS (Invitrogen) and 1\% penicillin-streptomycin solution. JAR cells were derived from human placental choriocarcinoma, 
which were purchased from Bioresource Collection and Research Center (Taiwan, Taiwan), and grown in RPMI 1640 medium with $10 \mathrm{mM}$ HEPES, $1 \mathrm{mM}$ sodium pyruvate, 10\% FBS and $1 \%$ penicillin-streptomycin solution. Ishikawa cells were grown in Minimum Essential Media (MEM) (Invitrogen) supplemented with 1\% non-essential amino acids (NEAA) + 5\% FBS and 1\% penicillin-streptomycin solution. These cells were cultured in a $5 \% \mathrm{CO}_{2}$ humidified incubator at $37^{\circ} \mathrm{C}$. After confluent growth, the attached cells were trypsinized and either cryopreserved or subcultured for further use.

\subsection{Generation of Variant PROK1 Expressing Plasmids and Transfection Experiments}

The variant sequence of PROK1 (V67I) was introduced into the WT Myc-DDK-tagged cDNA in a pCMV6-Entry vector (Origene Technologies, Inc., Rockville, MD, USA), which encodes the entire coding regions of human cDNA (GenBank NM_032414.2) of PROK1, using Stratagene's Quik Change II Site-directed Mutagenesis Kit (La Jolla, CA, USA). A vector control, pCMV6 empty vector, was constructed from pCMV6-PROK1 plasmid using sgfI and MluI digestion and the T4 ligation method. All constructs were verified by nucleotide sequencing. pCMV6 and PROK1 constructs were propagated in JM109 Escherichia coli. Transfection efficiency was tested on HEK293 (5 $\times 10^{5}$ cells) and HTR8/SVneo $\left(3 \times 10^{5}\right.$ cells) using $1 \mu \mathrm{g}$ of pCMV-EGFP (Clontech Laboratories, Inc., Palo, Alto, CA, USA) expressing plasmid and $3 \mu \mathrm{L}$ of TurboFect in six-well plates for 24 and $48 \mathrm{~h}$. The transfection efficiency is $90 \% \pm 10 \%$ in the two cell lines. The established constructs were transfected into HEK293 and HTR-8/SVneo cell lines by Turbofect for $24 \mathrm{~h}$ (Fermentas/Thermo Scientific, Waltham, MA, USA), and their expressions were confirmed by Western blotting. The PROKR1 and PROKR2 plasmids were constructed as reported in a previous study [18].

\subsection{Measurements of PROK1 Gene Expression}

\subsubsection{Quantitative Real-Time PCR (qRT-PCR) Analysis}

We extracted total RNA from scraped cells using the Trizol reagents (Invitrogen, Carlsbad, CA, USA) according to the manufacturer's instructions. The extracted RNA was spectrophotometrically quantified, and its quality was assessed by measuring the absorbance ratios at 260/280 and 260/230 $\mathrm{nm}$ using a GeneQuantTM Pro Spectrophotometer (GE Healthcare Biosciences, Piscataway, NJ, USA). Two micrograms of total RNA was reverse-transcribed using a SuperScript ${ }^{\circledR}$ Reverse Transcription kit (Invitrogen, Carlsbad, CA, USA) RNaseOut, dNTPs and random primers according to the manufacturer's protocols. The qPCR reactions were carried out in an Applied Biosystems StepOne Plus system (Applied Biosystems, Foster City, CA, USA). The primers used were the PROK1 sense primer, 5'-CATGCTCCTCCTAGTAACTG-3' ${ }^{\prime}$, the PROK1 antisense primer, 5'-TTTCCTGAAGAAGGGGAC-3', and the internal reference, GAPDH sense primer, $5^{\prime}$-ACAGTTGCCATGTAGACC- $3^{\prime}$, and the GAPDH antisense primer, $5^{\prime}$-TTTTTGGTTGAGCACAGG-3', which amplifies fragments of $190 \mathrm{bp}$ for PROK1 cDNA and $225 \mathrm{bp}$ for GAPDH cDNA (Sigma-Aldrich, Bornem, Belgium). A 10- $\mu \mathrm{L}$ reaction mixture containing cDNA, specific primers and Fast SYBR Green ${ }^{\circledR}$ Master Mix (Applied Biosystems, Carlsbad, CA, USA) was used in the PCR. Reactions were performed at $95^{\circ} \mathrm{C}$ for $20 \mathrm{~s}$, followed by 40 cycles of $95^{\circ} \mathrm{C}$ for $3 \mathrm{~s}$ and $60^{\circ} \mathrm{C}$ for $30 \mathrm{~s}$. To calculate the relative expression for each gene, the $2^{-\Delta \Delta C t}$ method was used to relate the $C_{t}$ values of PROK1 expression in each sample to the $C_{t}$ values of GAPDH.

\subsubsection{Immunoassay (ELISA)}

HEK293, HTR-8/SVneo, JAR, and Ishikawa cells $\left(3 \times 10^{5}\right)$ were transfected with pCMV vector, PROK1 wild type or V67I plasmid for $48 \mathrm{~h}$. Cell culture supernatant and cell lysate (cells were lysed with RIPA buffer) were harvested for an assay using an ELISA kit to assess the PROK1 concentration following the manufacturer's instructions (R and D Systems, Minneapolis, MN, USA). Briefly, supernatant or cell lysate were applied to the microplate coated with the capture antibody for $2 \mathrm{~h}$ at room temperature. Detection antibody conjugated to streptavidin-horseradish peroxidase 
was then applied, followed by the color development solution (tetramethylbezidine substrate) for $20 \mathrm{~min}$. Color development was terminated by addition of sulfuric acid, and the optical density was determined at $450 \mathrm{~nm}$ by a microplate reader (SpectraMa $\times 340$ PC384, Molecular Devices, Sunnyvale, CA, USA). A PROK1 standard (Biovision, Milpitas, CA, USA) was used for control, and calculation of the results was performed using computer software capable of generating a four parameter logistic (4-PL) curve-fit.

\subsection{Recombinant PROK1 and V67I by Concentrating Secreted Proteins}

HEK293 cells $\left(5 \times 10^{5}\right)$ were transfected in six-well plates with PROK1-WT or PROK1-V67I plasmid in DMEM with 1\% FBS for $48 \mathrm{~h}$. We then collected the culture medium to concentrate secreted protein using a centrifugal filter device, Amicon ${ }^{\circledR}$ Ultra4-3000 MWCO (Merck Millipore, Tullagreen, Carrigtwohill, Co., Cork, Ireland), under $3500 \mathrm{rpm}$ for $40 \mathrm{~min}$. We calculated the concentrated protein level using the ELISA method, as described above. The concentrated protein medium (conditioned medium (CM)) was stored at $-80{ }^{\circ} \mathrm{C}$, and its protein activity (WT and V67I) was compared with that of a PROK1 standard (Biovision, Milpitas, CA, USA) and tested for various cell functions, as described below.

\subsection{Cell Proliferation Assay}

The effect of PROK1 variant (V67I) on cell proliferation was assessed when compared with that of PROK1 wild-type and pCMV6 control. Cell lines were grown at $2 \times 10^{3}$ cells/well in a 96-well plate in DMEM or RPMI medium containing 10\% FBS for $24 \mathrm{~h}$. Cell proliferation was determined after one, two, three, and four days. Cell numbers were determined with PrestoBlue ${ }^{\mathrm{TM}}$ cell viability reagent (Invitrogen, Carlsbad, CA, USA). After adding $100 \mu \mathrm{L}$ of cell proliferation reagent in each well for $6 \mathrm{~h}$ at $37^{\circ} \mathrm{C}$ in a $\mathrm{CO}_{2}$ incubator, the absorbance at $570 \mathrm{~nm}$ (with $600 \mathrm{~nm}$ as the reference wavelength for normalization), reflecting the number of viable cells, was measured with a microplate reader (SpectraMax 340PC ${ }^{384}$, Molecular Devices, Sunnyvale, CA, USA). All the treatments were carried out in quadruplicate, and each experiment was carried out at least three times.

\subsection{Tube Formation Assay}

The effects of PROK1 wild-type and variant (V67I) on tube organization were assessed by growing transfected cells (HEK293 and HTR-8/SVneo) on Matrigel. Approximately $80 \mu \mathrm{L}$ ice-cold Matrigel (BD Biosciences, San Diego, CA, USA) was layered into each well of a 96-well plate. The Matrigel was allowed to completely solidify at $37^{\circ} \mathrm{C}$ for $1 \mathrm{~h}$. The transfected HEK293 $\left(5 \times 10^{4}\right.$ cells /well $)$ and HTR-8/SVneo $\left(3.5 \times 10^{4}\right.$ cells/well) cells were added and incubated at $37^{\circ} \mathrm{C}$ in an atmosphere of humidified $95 \%$ air $/ 5 \% \mathrm{CO}_{2}$ for 4 and $6 \mathrm{~h}$, respectively. Observations were made under an inverted photomicroscope to document the developmental stages. Tubal formation was assessed by measuring tubal length in four quadrants of high power fields in each well. Each assay was done in triplicate and each experiment was repeated at least three times. Quantification was measured with Image J software (Image J 1.47 h, Wayne Rasband, National Institute of Mental Health, Bethesda, MD, USA).

\subsection{Cell Invasion Assay}

To investigate the effects of PROK1 and its variant (V67I) on cell invasion, the transfected HEK293 $\left(1.5 \times 10^{5}\right)$ or HTR-8/SVneo $\left(1 \times 10^{4}\right)$ cells were trypsinized and re-suspended in serum-free medium and placed in the upper chamber coated with Matrigel $\left(1 \mathrm{mg} / \mathrm{mL}\right.$ at $37{ }^{\circ} \mathrm{C}$ for $1 \mathrm{~h}$; BD Biosciences, San Diego, CA, USA) in trans-well plates (millicell cell culture insert; $8 \mu \mathrm{m}$ pore size; Milipore, MA, USA) with or without PROK1 or V67I conditioned medium (1.0, 2.5, 5.0 nM). DMEM containing 10\% FBS was placed in the lower chamber. The cells were incubated for $20 \mathrm{~h}$ in a humidified atmosphere with $95 \%$ air and $5 \% \mathrm{CO}_{2}$ at $37{ }^{\circ} \mathrm{C}$. Invaded cells on the bottom side of the membrane were fixed with $100 \%$ cold methanol and stained with Giesmsa's azur eosin methylene blue solution (Merck, 
Darmatadt, Germany) and counted from a minimum of four high-power fields per insert under light microscopy. The data were expressed as the averages of three independent experiments.

\subsection{Intracellular Calcium Influx Assay}

Twenty-four hours after transfection, cells were harvested from plates using EDTA-trypsin, and washed with HBSS-based buffer (20 mM HEPES, $1 \mathrm{mM} \mathrm{MgSO}$, $3.3 \mathrm{mM} \mathrm{Na}_{2} \mathrm{CO}_{3}, 1.3 \mathrm{mM} \mathrm{CaCl}_{2}$, $2.5 \mathrm{mM}$ probenecid, $\mathrm{pH}$ 7.4) supplemented with $0.1 \%$ bovine serum album. Cells were loaded with $4 \mu \mathrm{M}$ calcium indicator Fluo-4 AM (Molecular Probes, Eugene, OR, USA) for $1 \mathrm{~h}$ at $37^{\circ} \mathrm{C}$. After washing twice, the cells were re-suspended to a concentration of $1 \times 10^{6}$ cells $/ \mathrm{mL}$. The green fluorescence emission of Fluo-4 was analyzed using FACSCalibur flow cytometry (BD Immunocytometry System), as described previously [18]. Following the establishment of a green fluorescence $\mathrm{Ca}^{2+}$ baseline, the indicated level of concentrated PROK1, V67I or PROK1 standard (Biovision, Milpitas, CA, USA) $(0.5,1$, 2.5 , or $5 \mathrm{nM}$ ) was added to the cell suspension to detect fluctuations in the green fluorescence.

\subsection{Statistical Analysis}

All values of the experimental assays were expressed as means \pm SEM. Differences between the groups were compared using the unpaired two-tailed $t$-test or one-way ANOVA, and a $p$ value of less than 0.05 was considered statistically significant.

\section{Conclusions}

We evaluated the function and possible regulatory mechanism of a common variant of PROK1 as a genetic modifier in early human pregnancy. Although PROK1-V67I has a similar functional effect to that of WT on cell behavior, gene expression at the transcript and protein levels is impaired. The results of this work provide an explanation for how a common, innocuous PROK1 variant could act epistatically with its receptor genes to interfere with the outcome of early human pregnancy. However, more research is needed to assess whether the clinical impact of the decreased protein production of PROK1-V67I is positive or negative. Considering the important role of PROK1 in pregnancy and the high prevalence of V67I in the general population, the findings of the present study may provide a common mechanism with regard to modulate the risk of various PROK1-related diseases.

Acknowledgments: This work was supported by grants from the National Science Council of the Republic of China (NSC- 99-2314-B-006-026-MY2 and NSC-101-2314-B-006-039-MY3).

Author Contributions: Study design, execution and manuscript drafting: Mei-Tsz Su; Study execution: Jyun-Yuan Huang, Hui-Ling Tsai; Statistical analysis and data interpretation: Yi-Chi Chen; Critical discussion and correspondence: Pao-Lin Kuo.

Conflicts of Interest: All authors have no conflicts of interest.

\section{References}

1. Ferrara, N.; LeCouter, J.; Lin, R.; Peale, F. EG-VEGF and Bv8: A novel family of tissue-restricted angiogenic factors. Biochim. Biophys. Acta 2004, 1654, 69-78. [CrossRef] [PubMed]

2. Ferrara, N.; Frantz, G.; LeCouter, J.; Dillard-Telm, L.; Pham, T.; Draksharapu, A.; Giordano, T.; Peale, F. Differential Expression of the Angiogenic Factor Genes Vascular Endothelial Growth Factor (VEGF) and Endocrine Gland-Derived VEGF in Normal and Polycystic Human Ovaries. Am. J. Pathol. 2003, 162, 1881-1893. [CrossRef]

3. Fraser, H.M.; Bell, J.; Wilson, H.; Taylor, P.D.; Morgan, K.; Anderson, R.A.; Duncan, W.C. Localization and Quantification of Cyclic Changes in the Expression of Endocrine Gland Vascular Endothelial Growth Factor in the Human Corpus Luteum. J. Clin. Endocrinol. Metab. 2005, 90, 427-434. [CrossRef] [PubMed]

4. Hoffmann, P.; Feige, J.J.; Alfaidy, N. Expression and Oxygen Regulation of Endocrine Gland-Derived Vascular Endothelial Growth Factor/Prokineticin-1 and Its Receptors in Human Placenta during Early Pregnancy. Endocrinology 2006, 147, 1675-1684. [CrossRef] [PubMed] 
5. LeCouter, J.; Kowalski, J.; Foster, J.; Hass, P.; Zhang, Z.; Dillard-Telm, L.; Frantz, G.; Rangell, L.; DeGuzman, L.; Keller, G.A.; et al. Identification of an angiogenic mitogen selective for endocrine gland endothelium. Nature 2001, 412, 877-884. [CrossRef] [PubMed]

6. Ngan, E.S.; Lee, K.Y.; Yeung, W.S.; Ngan, H.Y.; Ng, E.H.; Ho, P.C. Endocrine Gland-Derived Vascular Endothelial Growth Factor Is Expressed in Human Peri-implantation Endometrium, But Not in Endometrial Carcinoma. Endocrinology 2006, 147, 88-95. [CrossRef] [PubMed]

7. Evans, J.; Catalano, R.D.; Morgan, K.; Critchley, H.O.; Millar, R.P.; Jabbour, H.N. Prokineticin 1 Signaling and Gene Regulation in Early Human Pregnancy. Endocrinology 2008, 149, 2877-2887. [CrossRef] [PubMed]

8. Haouzi, D.; Mahmoud, K.; Fourar, M.; Bendhaou, K.; Dechaud, H.; De Vos, J.; Rème1, T.; Dewailly, D.; Hamamah, S. Identification of new biomarkers of human endometrial receptivity in the natural cycle. Hum. Reprod. 2009, 24, 198-205. [CrossRef] [PubMed]

9. Denison, F.C.; Battersby, S.; King, A.E.; Szuber, M.; Jabbour, H.N. Prokineticin-1: A Novel Mediator of the Inflammatory Response in Third-Trimester Human Placenta. Endocrinology 2008, 149, 3470-3477. [CrossRef] [PubMed]

10. Brouillet, S.; Hoffmann, P.; Feige, J.J.; Alfaidy, N. EG-VEGF: A key endocrine factor in placental development. Trends Endocrinol. Metab. 2012, 23, 501-508. [CrossRef] [PubMed]

11. Gorowiec, M.R.; Catalano, R.D.; Norman, J.E.; Denison, F.C.; Jabbour, H.N. Prokineticin 1 Induces Inflammatory Response in Human Myometrium: A Potential Role in Initiating Term and Preterm Parturition. Am. J. Pathol. 2011, 179, 2709-2719. [CrossRef] [PubMed]

12. Shaw, J.L.; Denison, F.C.; Evans, J.; Durno, K.; Williams, A.R.; Entrican, G.; Critchley, H.O.D.; Jabbour, H.N.; Horne, A.W. Evidence of prokineticin dysregulation in fallopian tube from women with ectopic pregnancy. Fertil. Steril. 2010, 94, 1601-1608. [CrossRef] [PubMed]

13. Hoffmann, P.; Saoudi, Y.; Benharouga, M.; Graham, C.H.; Schaal, J.P.; Mazouni, C.; Feige, J.J.; Alfaidy, N. Role of EG-VEGF in human placentation: Physiological and pathological implications. Cell. Mol. Life Sci. 2009, 13, 2224-2235. [CrossRef] [PubMed]

14. Alfaidy, N.; Hoffmann, P.; Gillois, P.; Gueniffey, A.; Lebayle, C.; Garçin, H.; Thomas-Cadi, C.; Bessonnat, J.; Coutton, C.; Villaret, L.; et al. PROK1 level in the follicular microenvironment: A new non-invasive predictive biomarker of embryo implantation. J. Clin. Endocrinol. Metab. 2015. [CrossRef] [PubMed]

15. Alfaidy, N.; Hoffmann, P.; Boufettal, H.; Samouh, N.; Aboussaouira, T.; Benharouga, M.; Feige, J.J.; Brouillet, S. The Multiple Roles of EG-VEGF/PROK1 in Normal and Pathological Placental Angiogenesis. Biomed. Res. Int. 2014, 2014, 451906. [CrossRef] [PubMed]

16. Su, M.T.; Lin, S.H.; Lee, I.W.; Chen, Y.C.; Hsu, C.C.; Pan, H.A.; Kuo, P.L. Polymorphisms of endocrine gland-derived vascular endothelial growth factor gene and its receptor genes are associated with recurrent pregnancy loss. Hum. Reprod. 2010, 25, 2923-2930. [CrossRef] [PubMed]

17. Su, M.T.; Lin, S.H.; Chen, Y.C.; Kuo, P.L. Gene-gene interactions and risk of recurrent miscarriages in carriers of endocrine gland-derived vascular endothelial growth factor and prokineticin receptor polymorphisms. Fertil. Steril. 2014, 102, 1071-1077. [CrossRef] [PubMed]

18. Su, M.T.; Lin, S.H.; Chen, Y.C.; Wu, L.W.; Kuo, P.L. Prokineticin receptor variants (PKR1-I379V and PKR2-V331M) are protective genotypes in human early pregnancy. Reproduction 2013, 146, 63-73. [CrossRef] [PubMed]

19. Andreasen, L.; Nielsen, J.B.; Christophersen, I.E.; Holst, A.G.; Sajadieh, A.; Tveit, A.; Haunsø, S.; Svendsen, J.H.; Schmitt, N.; Olesen, M.S. Genetic Modifier of the QTc Interval Associated With Early-Onset Atrial Fibrillation. Can. J. Cardiol. 2013, 29, 1234-1240.

20. Flanigan, K.M.; Ceco, E.; Lamar, K.M.; Kaminoh, Y.; Dunn, D.M.; Mendell, J.R.; King, W.M.; Pestronk, A.; Florence, J.M.; Mathews, K.D.; et al. LTBP4 genotype predicts age of ambulatory loss in duchenne muscular dystrophy. Ann. Neurol. 2013, 73, 481-488. [CrossRef] [PubMed]

21. Barry, E.L.; Poole, E.M.; Baron, J.A.; Makar, K.W.; Mott, L.A.; Sandler, R.S.; Ahnen, D.J.; Bresalier, R.S.; McKeown-Eyssen, G.E.; Ulrich, C.M. CYP2C9 Variants Increase Risk of Colorectal Adenoma Recurrence and Modify Associations with Smoking but Not Aspirin Treatment. Cancer Causes Control 2013, 24, 47-54. [CrossRef] [PubMed]

22. Solomon, O.; Bazak, L.; Levanon, E.Y.; Amariglio, N.; Unger, R.; Rechavi, G.; Eyal, E. Characterizing of functional human coding RNA editing from evolutionary, structural, and dynamic perspectives. Proteins 2014, 82, 3117-3131. [CrossRef] [PubMed] 
23. Brouillet, S.; Murthi, P.; Hoffmann, P.; Salomon, A.; Sergent, F.; de Mazancourt, P.; Dakouane-Giudicelli, M.; Dieudonné, M.N.; Rozenberg, P.; Vaimanet, D.; et al. EG-VEGF controls placental growth and survival in normal and pathological pregnancies: Case of fetal growth restriction (FGR). Cell. Mol. Life Sci. 2013, 70, 511-525. [CrossRef] [PubMed]

24. Kaufmann, P.; Black, S.; Huppertz, B. Endovascular Trophoblast Invasion: Implications for the Pathogenesis of Intrauterine Growth Retardation and Preeclampsia. Biol. Reprod. 2003, 69, 1-7. [CrossRef] [PubMed]

25. Bălu, S.; Pirtea, L.; Gaje, P.; Cîmpean, A.M.; Raica, M. The immunohistochemical expression of endocrine gland-derived-VEGF (EG-VEGF) as a prognostic marker in ovarian cancer. Rom. J. Morphol. Embryol. 2012, 53, 479-483. [PubMed]

26. Goi, T.; Nakazawa, T.; Hirono, Y.; Yamaguchi, A. Prokineticin 1 expression in gastrointestinal tumors. Anticancer Res. 2013, 33, 5311-5315. [PubMed]

27. Ren, L.; Guo, X.; Shao, X.; Li, H.; Yao, H. Endocrine gland-derived vascular endothelial growth factor modulates proliferation, apoptosis and migration in pancreatic cancer cells. Mol. Med. Rep. 2015, 11, 4279-4284. [CrossRef] [PubMed]

28. Torres, C.; Linares, A.; Alejandre, M.J.; Palomino-Morales, R.J.; Caba, O.; Prados, J.; Aránega, A.; Delgado, J.R.; Irigoyen, A.; Martínez-Galánet, J.; et al. Prognosis Relevance of Serum Cytokines in Pancreatic Cancer. BioMed Res. Int. 2015, 2015, 518284. [CrossRef] [PubMed]

29. Nakazawa, T.; Goi, T.; Hirono, Y.; Yamaguchi, A. Prokineticin 1 protein expression is a useful new prognostic factor for human sporadic colorectal cancer. Ann. Surg. Oncol. 2015, 22, 1496-1503. [CrossRef] [PubMed]

30. Pasquali, D.; Rossi, V.; Staibano, S.; de Rosa, G.; Chieffi, P.; Prezioso, D.; Mirone, V.; Mascolo, M.; Tramontano, D.; Bellastella, A.; et al. The endocrine-gland-derived vascular endothelial growth factor (EG-VEGF)/Prokineticin 1 and 2 and receptor expression in human prostate: Up-regulation of EG-VEGF/Prokineticin 1 with malignancy. Endocrinology 2006, 147, 4245-4251. [CrossRef] [PubMed]

31. Swaggart, K.A.; Demonbreun, A.R.; Vo, A.H.; Swanson, K.E.; Kim, E.Y.; Fahrenbach, J.P.; Holley-Cuthrell, J.; Eskin, A.; Chen, Z.; Squire, K.; et al. Annexin A6 modifies muscular dystrophy by mediating sarcolemmal repair. Proc. Natl. Acad. Sci. USA 2014, 111, 6004-6009. [CrossRef] [PubMed]

32. Sproule, T.J.; Bubier, J.A.; Grandi, F.C.; Sun, V.Z.; Philip, V.M.; McPhee, C.G.; Adkins, E.B.; Sundberg, J.P.; Roopenian, D.C. Molecular Identification of Collagen 17a1 as a Major Genetic Modifier of Laminin Gamma 2 Mutation-Induced Junctional Epidermolysis Bullosa in Mice. PLoS Genet. 2014, 10, e1004068. [CrossRef] [PubMed]

33. Cooper-Knock, J.; Shaw, P.J.; Kirby, J. The widening spectrum of C9ORF72-related disease; genotype/phenotype correlations and potential modifiers of clinical phenotype. Acta Neuropathol. 2014, 127, 333-345. [CrossRef] [PubMed]

34. Van Blitterswijk, M.; Mullen, B.; Heckman, M.G.; Baker, M.C.; DeJesus-Hernandez, M.; Brown, P.H.; Murray, M.E.; Hsiung, G.H.R.; Stewartc, H.; Karydasd, A.M.; et al. Ataxin-2 as potential disease modifier in C9ORF72 expansion carriers. Neurobiol. Aging 2014, 35, 2421.e13-2421.e17. [CrossRef] [PubMed]

35. Heydemann, A.; Huber, J.M.; Demonbreun, A.; Hadhazy, M.; McNally, E.M. Genetic background influences muscular dystrophy. Neuromuscul. Disord. 2005, 15, 601-609. [CrossRef] [PubMed]

(C) 2016 by the authors; licensee MDPI, Basel, Switzerland. This article is an open access article distributed under the terms and conditions of the Creative Commons by Attribution (CC-BY) license (http://creativecommons.org/licenses/by/4.0/). 